\title{
Analysis of Nod-Factor-Induced Calcium Signaling in Root Hairs of Symbiotically Defective Mutants of Lotus japonicus
}

\author{
Hiroki Miwa, Jongho Sun, Giles E. D. Oldroyd, and J. Allan Downie \\ John Innes Centre, Colney Lane, Norwich NR4 7UH, U.K. \\ Submitted 27 January 2006. Accepted 24 March 2006.
}

\begin{abstract}
Nodulation (Nod)-factor signaling molecules are essential for rhizobia to initiate the nitrogen-fixing symbiotic interaction with legumes. Using a dual dye ratiometric calcium imaging technique, we have shown that $10 \mathrm{nM}$ Nod factor added to roots of Lotus japonicus seedlings induces an intracellular calcium increase (calcium flux) that precedes oscillations in intracellular calcium (calcium spiking). The calcium flux was not observed with 1 or $0.1 \mathrm{nM}$ Nod factor, which did induce calcium spiking. The calcium flux was variable in timing of initiation and duration and was observed in approximately half of the root hairs examined. Representatives from 11 complementation groups of symbiotically defective mutants were analyzed for the calcium flux. Mutants from four groups (sym6, ccamk, sym35, and nin) which retained calcium spiking all showed a normal calcium flux. Two classes of mutants ( $n f r 1$ and $n f r 5)$ lacked both calcium influx and calcium spiking, whereas five classes of mutants (symRK, castor, pollux, nup133, and sym24) defective for calcium spiking retained a calcium flux. There was no correlation between calcium spiking and induction of root hair deformation by Nod factor. We propose that increased bacterial numbers within infection foci in root hairs leads to accumulation of Nod factor to sufficient levels to activate the calcium flux, and this may drive infection thread growth.
\end{abstract}

Additional keyword: Medicago, Mesorhizobium, nodule.

Legume-nodulating rhizobia produce nodulation (Nod) factors that are oligomers of four or five $\beta-1-4$ linked $N$-acetyl glucosamine residues in which the terminal nonreducing residue is replaced by various $\mathrm{N}$-linked fatty acids replacing the acetyl group (Downie 1998). These acyl groups, along with various substitutions (such as acetyl, carbamoyl, sulphatyl, and modified sugars) on the sugar backbone, are the primary determinants of the range of legumes nodulated by a given rhizobial strain (Perret et al. 2000). These Nod factors are produced in response to flavonoids secreted from legume roots. When purified Nod factors are added to the roots of appropriate legume seedlings, they induce root hair deformation, induction of early nodulation genes (Charron et al. 2004; Cook et al. 1995; Journet et al. 1994), activation of phospholipase $C$ and phospholipase $D$

Corresponding author: J. A. Downie; Fax: (44) 1603 450207; E-mail: allan.downie@bbsrc.ac.uk

Current address of H. Miwa: Biotechnology Research Center, University of Tokyo, Yayoi 1-1-1 Bunkyo-ku, Tokyo 113-8657, Japan. (den Hartog et al. 2001), and, in some cases, nodule morphogenesis (Truchet et al. 1991).

A depolarization of the plasma membrane of root hair cells causing a decrease in membrane potential of 10 to $15 \mathrm{mV}$ is the earliest observed response to Nod factors and occurs within 1 min of addition (Ehrhardt et al. 1992; Kurkdjian 1995; Radutoiu et al. 2003). Using ion-selective microelectrodes, it was shown this depolarization is a function of an influx of calcium across the plasma membrane, immediately followed by chloride and then potassium efflux, along with a cytoplasmic alkalinization. (Felle et al. 1996, 1998). Pharmacological experiments have confirmed that the rise in cytoplasmic calcium is necessary for the chloride efflux and membrane depolarization (Felle et al. 1999), and the calcium flux requires $1 \mathrm{nM}$ Nod factor for half maximal induction (Felle et al. 2000). Re polarization of the plasma membrane occurred in two steps: an initial fast phase occurring within 30 to $60 \mathrm{~s}$ and a slower second phase lasting for variable times up to approximately 15 min (Kurkdjian 1995).

The Nod-factor-induced changes in intracellular calcium also have been observed using various calcium-sensitive dyes in different legumes. Increases in root hair calcium were observed in Vicia sativa using acid loading of Indo-1 (de Ruijter et al. 1998), in Phaseolus vulgaris and Vigna unguiculata root hairs using micro-injected dextran-linked Fura-2 (Cardenas et al. 1999; Gehring et al. 1997), and in Medicago sativa, M. truncatula, and Pisum sativum using micro-injected dextran-linked Oregon green (Ehrhardt et al. 1996; Shaw and Long 2003; Wais et al. 2000; Walker et al. 2000). In M. truncatula, the calcium flux appeared to be biphasic, with an initial increase in calcium followed by an elevated level of calcium lasting for several minutes (Ehrhardt et al. 1996; Shaw and Long 2003; Wais et al. 2000; Walker et al. 2000). This elevated level of intracellular calcium may correspond to the second phase of membrane depolarization measured using microelectrodes.

Oscillations in cytosolic calcium (termed calcium spiking) occur 10 to $15 \mathrm{~min}$ after Nod factor addition (Ehrhardt et al. 1996), following the calcium flux (Shaw and Long 2003; Walker et al. 2000). Calcium spiking has been observed in $M$. truncatula (Wais et al. 2000), M. sativa (Ehrhardt et al. 1996), P. sativum (Walker et al. 2000), Phaseolus vulgaris (Cardenas et al. 1999), and Lotus japonicus (Harris et al. 2003). The calcium flux and calcium spiking responses can be separated: calcium spiking is induced at concentrations of Nod factor two or three orders of magnitude lower than that required for induction of the calcium flux (Shaw and Long 2003) and, in both Pisum sativum and M. truncatula, calcium spiking is induced by Nod-factor-like molecules without the induction of a calcium flux (Shaw and Long 2003; Walker et al. 2000). These observations suggest that there is a lower stringency of Nod factor 
perception required for induction of calcium spiking, whereas a relatively high concentration and specific Nod factor structures are required to induce the calcium influx.

Various symbiosis-defective legume mutants have been ana lyzed using calcium-responsive fluorescent dyes to determine whether the mutations affect Nod-factor-induced changes in intracellular calcium in root hairs. In $M$. truncatula and $P$. sati $v u m$, there are three identified genes that are required for the early establishment of both rhizobial and mycorrhizal symbioses, and mutations in two of these genes block the induction of calcium spiking, whereas mutation of the other does not (Wais et al. 2000; Walker et al. 2000). The genes not required for cal cium spiking (Dmi3 and Sym9) encode a chimeric calciumcalmodulin-dependent protein kinase $(\mathrm{CCaMK})$ that has been proposed to integrate calcium spiking into downstream signal ing leading to gene induction (Levy et al. 2004; Mitra et al. 2004a; Oldroyd and Downie 2004). The other two genes re quired for calcium spiking, Dmil and Dmi2, encode proteins predicted to form an ion channel (Ane et al. 2004) and a leucinerich repeat receptor-like kinase (Endre et al. 2002), respectively. Mutations in these two genes altered the calcium flux such that the initial phase of flux was seen, but the second phase was absent; in contrast, the $d m i 3$ mutant showed a normal calcium flux (Shaw and Long 2003). In M. truncatula and P. sativum, mutation of one other gene ( $N f p$ and Sym10, respectively) blocked Nod-factor-induced calcium spiking (Ben Amor et al. 2003; Walker et al. 2000). These genes are not required for the mycorrhizal symbiosis (Ben Amor et al. 2003; Duc et al. 1989), and the pea Sym10 gene is the orthologue of the L. japonicus gene $N f r 5$ that has been proposed to encode part of a Nod-factor receptor (Madsen et al. 2003). The $n f p$ mutant is the only M. truncatula mutant which has been shown to have neither calcium flux nor calcium spiking in response to added Nod factor in accord with it being a likely component of Nod factor recognition (Ben Amor et al. 2003). The fact that mutations in Nfr5, Sym10, and Nfp do not affect mycorrhization (Ben Amor et al. 2003; Duc and Messager 1989; Radutoiu et al. 2003) supports the model that there are different signaling inputs from rhizobia and mycorrhizal symbionts to activate a downstream pathway that is shared by both symbioses (Ben Amor et al. 2003; Radutoiu et al. 2003; Wais et al. 2000; Walker et al. 2000).

Whereas, in both $M$. truncatula and $P$. sativum, only three genes have been identified as being required for initiation of both rhizobial and mycorrhizal symbioses, seven $L$. japonicus genes (SymRK, Castor, Pollux, Nup133, Sym6, CcamK, and Sym24) have been identified as being required for both sym bioses (Kistner et al. 2005). Furthermore, two L. japonicus genes ( Nfrl and Nfr5) have been proposed to encode a receptor for Nod factors (Madsen et al. 2003; Radutoiu et al. 2003). Pollux is orthologous to Dmil and, together with Castor (for which no orthologue has been identified), has been proposed to encode part of an ion-selective pore, possibly in the plastid (ImaizumiAnraku et al. 2005). SymRK is the orthologue of Dmi2 and has been shown to have kinase activity (Yoshida and Parniske 2005). Nup133 encodes a proposed nucleoporin (Kanamori et al. 2006) and no equivalent mutant has been de fined in M. truncatula or $P$. sativum. Sym15 encodes the CCaMK and is orthologous to Dmi3 (Tirichine et al., in press). The identities of the Sym6 and Sym 24 genes have not yet been published.

Using extracellular microelectrodes, it was shown that mutation of Nfr5 in L. japonicus blocked the initial Nod-factorinduced depolarization of the root hair membrane and mutation of $\mathrm{Nfrl}$ severely reduced the response (Radutoiu et al. 2003). Analysis of calcium changes using imaging of calcium-sensitive fluorescent dyes has revealed that mutations in Castor, Pollux, or Nup133 block Nod-factor-induced calcium spiking, (Harris et al. 2003; Imaizumi-Anraku et al. 2005; Kanamori et al.
2006) whereas, a sym30 mutant, which is allelic to sym6 (Sandal et al. 2006), retained Nod-factor-induced calcium spiking (Harris et al. 2003). In addition to these mutants, there are other L. japonicus mutants, such as nin (Schauser et al. 1999) and sym35 (Kawaguchi et al. 2002; Sandal et al. 2006), which are defective for the symbiosis with rhizobia but have normal mycorrhizal symbiotic development. Thus, it appears that, in L. japonicus, there are several additional genes required for the rhizobial symbiosis that have not yet been identified as being required in $M$. truncatula or $P$. sativum.

Given the diversity of nodulation-defective mutants in $L$. japonicus, we set out to determine whether we could measure a Nod-factor-induced calcium influx in L. japonicus and to identify how the legume symbiotic mutations affect the calcium influx and calcium spiking. We found that mutations in seven loci blocked Nod-factor-induced calcium spiking, whereas only those mutations affecting the predicted Nod-factor receptor totally blocked the calcium influx. We propose a model suggesting that the calcium influx is required for infection thread initiation and that the calcium flux may occur only after trapped bacteria accumulating in a curled root hair generate sufficient Nod factor to induce the calcium flux.

\section{RESULTS}

\section{Nod factor induces a calcium flux}

in wild-type $L$. japonicus root hairs.

Root hair cells of $L$. japonicus were iontophoretically injected with the dyes Oregon green and Texas red and the fluorescent signals of both dyes were imaged simultaneously for at least 40 min. In this analysis, background fluctuations caused by cytoplasmic streaming were greatly reduced by ratiometric analysis of Oregon green, which alters its fluorescence with bound calcium, relative to Texas red, which shows no fluorescence changes. Typical changes in Oregon green fluorescence due to cytoplasmic streaming are illustrated in the sequential images shown in Figure 1A; only cells showing such active calcium streaming were used for analyses of calcium changes. Calcium spiking was induced clearly in root hairs of $L$. japonicus within 30 min of treatment with Nod factor from Mesorhizobium loti R7A at concentrations of $1 \mathrm{nM}(14 / 14$ cells) and $0.1 \mathrm{nM}(9 / 9$ cells). However, at these Nod factor concentrations, no clear calcium change prior to calcium spiking was observed (data not shown). When Nod factor was added to roots at a final concentration of $10 \mathrm{nM}$, there was an increase in cytoplasmic calcium concentration prior to calcium spiking in some cells (Fig. 1B). The characteristics of this calcium flux were found to be variable from cell to cell: a rapid increase in calcium immediately after Nod factor addition and a plateau lasting for approximately $10 \mathrm{~min}$ (e.g., trace 1, Fig. 1B); a rapid calcium increase with a significant delay after Nod factor addition (e.g., trace 2, Fig. 1B); a relatively transient increase in calcium (e.g., trace 4, Fig. 1B); and no discernable calcium flux, but clear calcium spiking (e.g., trace 5 Fig. 1B). In all, 13 of 29 cells from 20 plants showed a calcium change preceding calcium spiking and in no case did we observe a calcium flux without induction of calcium spiking. Some cells clearly showed the biphasic calcium flux response described previously in Medicago truncatula (Shaw and Long 2003) and calcium spiking usually initiated shortly after the end of the second phase of the calcium flux. However, due to the variability from cell to cell, it was very difficult to determine whether this response was biphasic in all cells.

\section{Calcium flux occurs}

in nodulation mutants retaining calcium spiking.

A calcium flux was induced before calcium spiking when Nod factor was added to the roots of the sym30/sym6, ccamk, 
sym35, and nin mutants of L. japonicus (Fig. 2). Data on calcium spiking in the ccamk and sym30 (allelic to sym6) mutants have been described previously (Harris et al. 2003) (Tirichine et al., in press). Some root hair cells in all of these mutants showed a clear Nod-factor-induced increase in calcium prior to the onset of calcium spiking (Fig. 2) and the data from all of the cells analyzed are summarized in Figure 3. In each mutant, a calcium influx was seen in approximately half the cells tested and we could discern no significant difference in the characteristics of the calcium influx in the mutants compared with that seen in wild type (Fig. 3).

\section{Analysis of calcium responses in mutants} of the putative Nod factor receptor.

Nodulation-defective L. japonicus carrying mutations in $N f r 1$ or $N f r 5$ showed no morphological changes and lacked or

A

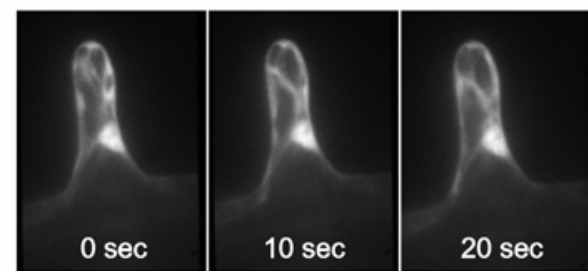

B

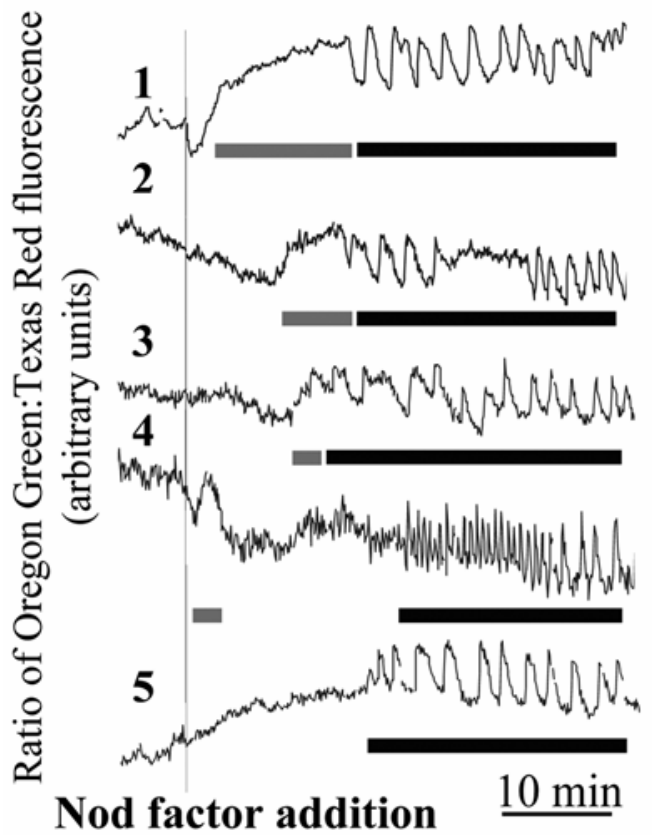

Fig. 1. Changes of intracellular calcium in wild-type Lotus japonicus root hairs imaged using ratiometric fluorescence. A, Before nodulation (Nod)factor addition, fluorescence was imaged in root hair cells that had been microinjected with a mixture of dextran-linked Oregon Green and Texas Red. Only cells showing normal cytoplasmic streaming after microinjection were used, and such streaming can be seen in the sequential images of Oregon green fluorescence collected at 10-s intervals prior to the addition of Nod-factor. B, Nod factor was added as indicated to a final concentration of $10 \mathrm{nM}$ to seedlings and the ratios (arbitrary units) of fluorescence of Oregon Green (calcium sensitive) to Texas Red (reference) were calculated every $5 \mathrm{~s}$ for $>40 \mathrm{~min}$. Such data are shown for five root hairs specifically chosen to illustrate the different types of responses we observed. The gray bars are drawn to illustrate the different types of changes that we have decided to call a calcium flux and the black bars are drawn under calcium spiking. showed greatly reduced changes in extracellular $\mathrm{pH}$ and membrane potential in response to Nod factor (Radutoiu et al. 2003). We found that Nod factor did not induce calcium spiking in root hairs of $n f r 5-3$ (0/10 cells) or in any of the $n f r l$ alleles tested (nfrl-1, nfrl-2, and $n f r l-3,0 / 47$ cells total). Traces of the $n f r 5-3$ mutant were relatively flat and no fluctuations corresponding to a calcium flux was seen (Fig. 4). Similarly, no significant calcium influx was observed with the $n f r l-1$ (Fig. 4)

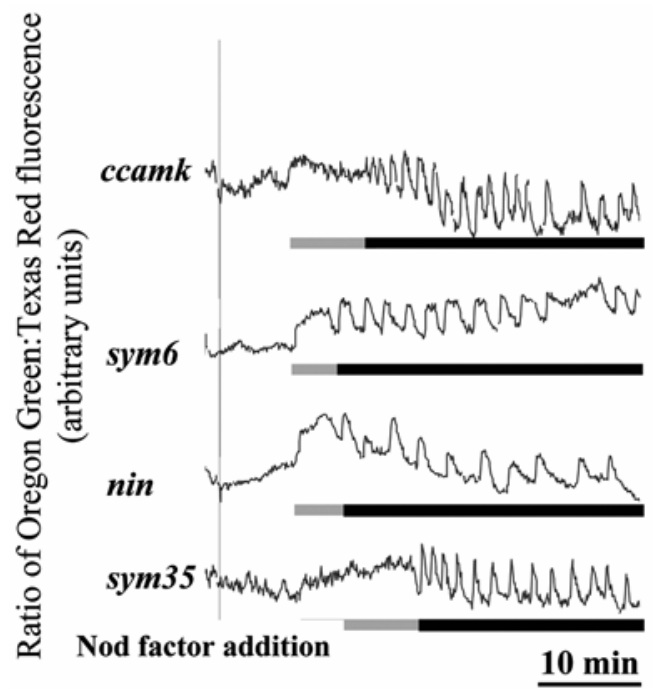

Fig. 2. Changes of intracellular calcium in mutants of Lotus japonicus that induce calcium spiking. Representative traces of calcium changes after nodulation (Nod) factor $(10 \mathrm{nM})$ addition are shown as fluorescence ratio data; ratios (arbitrary units) of fluorescence of Oregon Green (calcium sensitive) to Texas Red (reference) were calculated every $5 \mathrm{~s}$ for $>40 \mathrm{~min}$. Representative traces showing the calcium flux (gray bar) preceding calcium spiking (black bar) are shown for the ccamk-1, sym6-2, nin-7, and sym35 mutants. Not all cells showed the calcium flux.

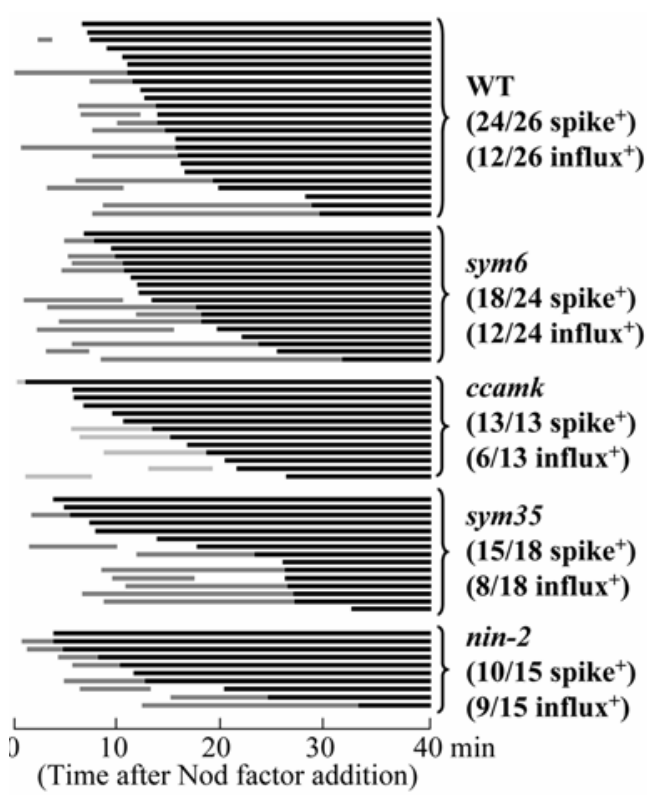

Fig. 3. Time of induction and duration of the calcium flux relative to calcium spiking in wild type and mutants that induce calcium spiking. The data from traces showing calcium changes similar to those in Figures $1 \mathrm{~B}$ and 2 are summarized using gray or black bars to indicate calcium flux or spiking, respectively. The number of cells showing calcium spiking or calcium flux is shown in parentheses as a fraction of the total number of cells analyzed. The data with the sym6 and ccamK mutants are a compilation of results with the following alleles (with numbers of each tested in parentheses): sym6-1 (19), sym30 (allelic to sym6) (5), ccamk-1 (5), and camk-2 (8). 
and $n f r 1-3$ (data not shown) mutant alleles. The $n f r 1-2$ mutant did occasionally show an apparent transient decrease (rather than increase) in calcium in 5 of 18 cells and one of these is illustrated (Fig. 4). However, the changes were relatively small and may not be significant, although they do mirror the extracellular alkalinization (rather than acidification) observed previously with this allele (Radutoiu et al. 2003) and, therefore, may be an altered response to the Nod-factor signal. The data obtained with the $n f r 5-3, n f r l-1$, and $n f r l-3$ mutants show that, in the absence of putative Nod-factor-receptors, Nod factor did not significantly change intracellular calcium to levels that could be detected by the methods used here.

\section{Analysis of calcium flux in mutants lacking calcium spiking.}

Other genes in which mutations are known to block Nodfactor-induced calcium spiking are Castor and Pollux, which encode a predicted ion channel (Imaizumi-Anraku et al. 2005), and NUP133, which encodes a predicted nucleoporin (Kanamori et al. 2006). In addition, we show here that the sym 24 mutant lacks Nod-factor-induced calcium spiking (Fig. 4), and this was observed in all 23 cells tested from 18 separate plants (Fig. 5).

We analyzed the timing and duration of any calcium changes in the L. japonicus seedlings carrying mutations in SymRK, Castor, Pollux, Nup133, and Sym24. In all cases, we observed some cells that showed a clear change in the ratio of Oregon Green/Texas Red fluorescence, indicating Nod-factorinduced changes in calcium within root hair cells (Fig. 4). As had been seen with the wild type, the timing of the calcium changes and their duration varied significantly even between

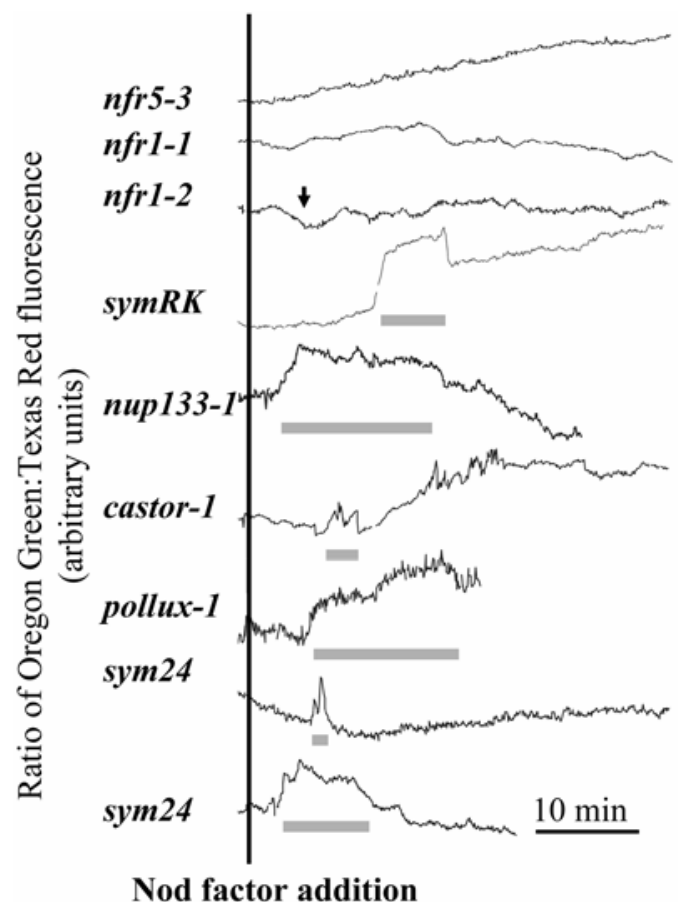

Fig. 4. Changes of intracellular calcium in mutants of Lotus japonicus that do not induce calcium spiking. Representative traces of calcium changes after nodulation (Nod) factor (10 nM) addition are shown as fluorescence ratio data; ratios (arbitrary units) of fluorescence of Oregon Green (calcium sensitive) to Texas Red (reference) were calculated every $5 \mathrm{~s}$ for $>40$ min. Representative traces show the calcium flux (gray bar) obtained with the various mutants as described on the figure. The $n f r l-2$ mutant shows a slight decrease in fluorescence approximately $3 \mathrm{~min}$ after Nod factor induction (arrow), and similar effects were seen with 4 other cells out of the total of 18 cells analyzed. plants carrying the same mutation (Fig. 4; illustrated with two traces obtained with the sym 24 mutant). We could detect no significant differences in the characteristics of the fluorescence changes compared with those seen with the wild type and all of the other mutants (Figs. 4 and 5). Based on the summary data shown in Figure 5, the only quantifiable difference was that the fraction of cells showing the calcium flux was lower than that seen with those plants that induced calcium spiking; only approximately a quarter to a third of the root hairs in these mutants showed a calcium flux compared with approximately half of those in plants that showed calcium spiking.

\section{Root hair deformation phenotypes in the mutants.}

It has been proposed that the induction of root hair deformation by Nod factor is on a separate pathway from those genes required for early nodulation gene expression and, by implication, calcium spiking, based on data from $M$. truncatula (Esseling et al. 2004). There are more mutants of L. japonicus defective for calcium spiking than are available in $M$. truncatula; therefore, we analyzed all of the mutants described above for root hair deformation in response to Nod factor. All of the mutants were grown in the same way as had been used for analysis of calcium changes. A range of root hair responses were observed in these mutants (e.g., strong swelling, intensive waving, and branching). We have observed that the phenotypes of root hair deformation in L. japonicus varied among the alleles and also can be affected by the growth conditions.

Root hair responses of these mutants fell into three major groups: no morphological changes (nfrl-1, nfrl-2, and nfr5-3) (Fig. 6; data not shown); root hair deformation similar to wild type (sym24, nin, and sym35) (Fig. 6); and root hair deformation with greater levels of tip swelling and excessive branching from the middle of root hairs compared with the wild type (symRK-3, symRK-7, nup133-1, nup133-3, castor-1, castor-3, pollux-1, pollux-2, ccamk-1, ccamk-2, sym6-2, and sym30) (Fig. 6; data not shown but summarized in Table 1). The strength of root hair responses to Nod factor in these mutants was variable.

\section{DISCUSSION}

It is evident from the work described here that, whereas mutations in seven separate loci can block Nod-factor-induced calcium spiking in the root hairs of L. japonicus, only two of these loci ( $N f r 1$ and $N f r 5$ ) are required for the observed Nod-

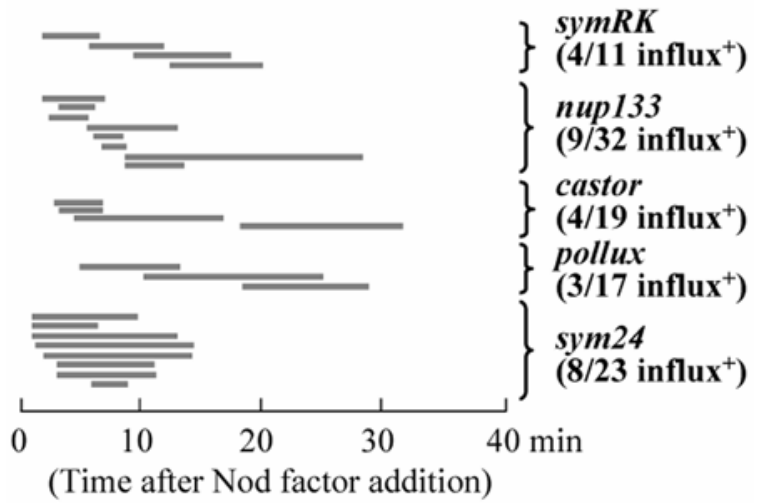

Fig. 5. Time of induction and duration of the calcium flux in Lotus japonicus mutants which do not induce calcium spiking. The data from traces similar to those in Figure 4 are summarized using gray bars to indicate calcium flux. The number of cells showing a calcium flux is shown in parentheses as a fraction of the total number of cells analyzed. The data are a compilation of results with the following alleles (with numbers of each tested in parentheses): symRK-3 (4), symRK-7 (6), nup133-1 (7), nup133-3 (9); castor-1 (7), castor-3 (7); pollux-1 (7), pollux-2 (10), and sym24 (23). 
factor-induced calcium flux that can be detected prior to calcium spiking. The $n f r 5$ mutant lacking this calcium flux already has been shown to be lacking Nod-factor-induced membrane depolarization and associated extracellular alkalinization, whereas the $n f r l-1$ mutant showed strongly attenuated responses and the nfrl-2 mutant showed some extracellular acidification and a delayed and attenuated membrane depolarization (Radutoiu et al. 2003). The lack of significant Nod-factor-induced changes in intracellular calcium (either flux or spiking) is consistent with the proposal that the $N f r 5$ and $N f r l$ gene products may be directly involved in Nod-factor perception (Radutoiu et al. 2003). The $n f p$ mutant of $M$. truncatula behaves in a similar manner to these mutants in that the mutation blocks both the calcium flux and calcium spiking (Ben Amor et al. 2003).

At least five other genes (SymRK, Castor, Pollux, Nup133, and Sym24) are required for induction of calcium spiking, presumably after the initial recognition of Nod factor, because a calcium flux could be identified in at least some cells of all of these mutants, even though no calcium spiking was observed. In M. truncatula, mutation of Dmil or Dmi2, the orthologues of Castor and SymRK, respectively, resulted in plants which could induce the initial phase of the flux (rapid increase of calcium), but the mutants failed to maintain the second phase of the calcium flux (sustained high calcium levels) (Shaw and Long 2003). In L. japonicus, the timing of induction of the calcium flux and its maintenance were significantly more variable than seen with $M$. truncatula and we did not see such clear differentials in either the wild type or mutants. This may reflect a difference in the plant species or, possibly, a mechanistic difference.

All five of the genes that are required for calcium spiking but not calcium influx are required for normal mycorrhization and downstream gene induction (Imaizumi-Anraku et al. 2005; Kanamori et al. 2006; Kistner et al. 2005; Stracke et al. 2002).
These genes encode a transmembrane leucine rich repeat receptor-like kinase (SymRK) (Stracke et al. 2002; Yoshida and Parniske 2005), two transmembrane channel-like proteins (Castor and Pollux) (Imaizumi-Anraku et al. 2005), and nucleoporin (Nup133) (Kanamori et al. 2006). The predicted role of the Sym24 gene product has not yet been described. There is no formal proof as to relative order of action of these components in the Nod-factor signaling pathway (Fig. 7); it is clear that Nfrl is epistatic to SymRK (Radutoiu et al. 2003); however, the lack of clear phenotypic differences among the five mutants will make it difficult to define epitasis relationships.

The observation that $\mathrm{Nfr} 1$ and $\mathrm{Nfr} 5$ are predicted kinases in the plasma membrane implies that they probably have specific substrates, and SymRK, which has been shown to be a plasma membrane located kinase itself (Yoshida and Parniske 2005), is one potential candidate. It seems unlikely, based on their predicted locations (Imaizumi-Anraku et al. 2005; Kanamori et al. 2006), that Castor and Pollux, which are thought to be in the plastid membrane, or Nup133, which is thought to be in the nuclear membrane, are targets of phosphorylation by Nfr1, Nfr5, or SymRK. This suggests that there are likely to be components of the signaling pathway that have not yet been identified. This is important because a key question is how Nod factor binding (presumably by Nfr1 and Nfr5) is coupled to induction of calcium spiking. This probably is a function of a secondary messenger, such as inositol phosphates, and this is supported by a probable role for PLC and PLD in Nod-factor signaling based on their activation by Nod factors and the inhibition of calcium spiking and early nodulation gene expression by phospholipase inhibitors (Charron et al. 2004; den Hartog et al. 2001; Engstrom et al. 2002; Walker et al. 2000)

In $M$. truncatula, microarray analyses have shown that seedlings carrying mutations in genes upstream of calcium spiking
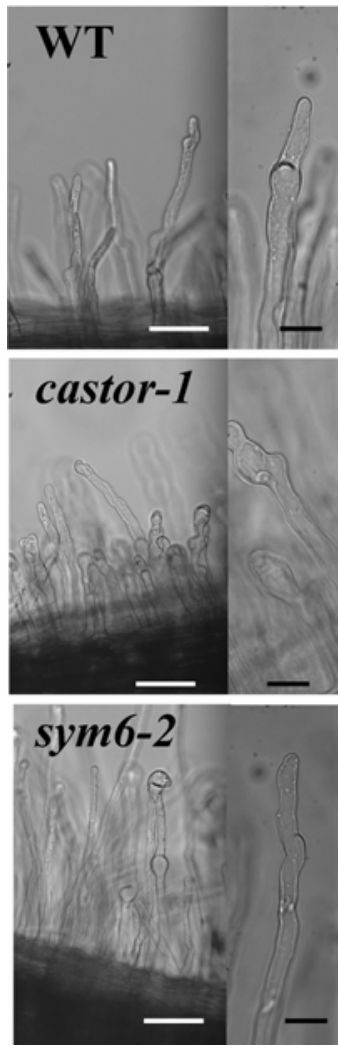
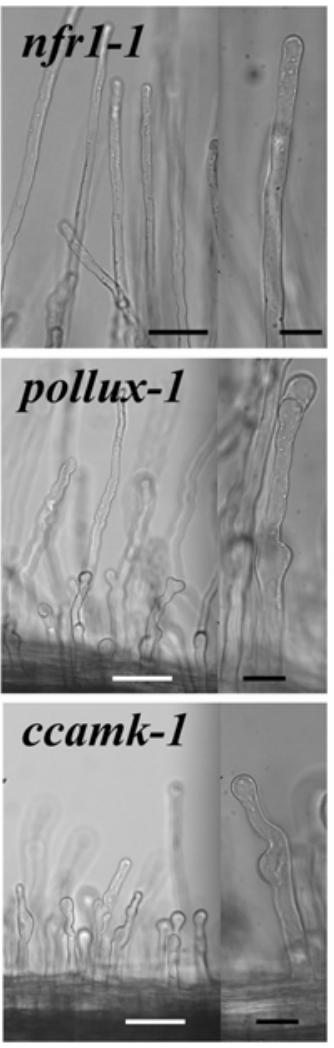
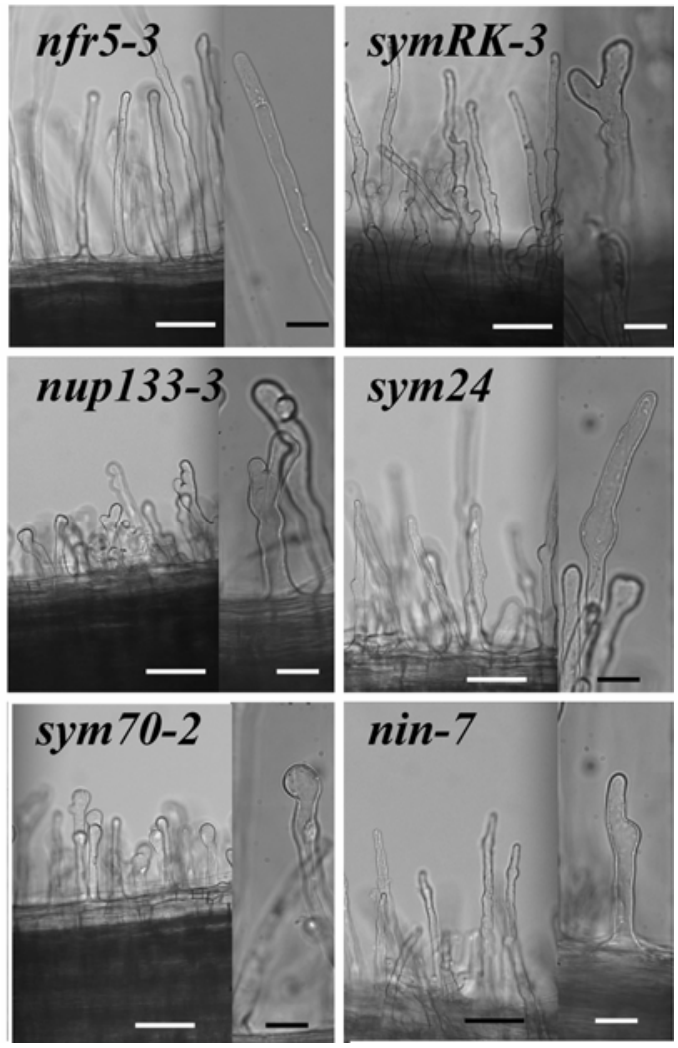

Fig. 6. Induction of root hair deformation in Lotus japonicus mutants. Nodulation (Nod) factor (10 nM) was added to the roots of seedlings grown under the same conditions as used for calcium analysis and root hair deformation was analyzed 18 to $24 \mathrm{~h}$ after Nod factor was added. Scale bars: $50 \mu \mathrm{m}$ for larger images, $10 \mu \mathrm{m}$ for smaller images. 
(nfp, dmil, and dmi2) show the same defects in gene induction by Nod factor as seedlings carrying mutations in those genes (dmi3, nsp 1, and $n s p 2$ ) that lie downstream of calcium spiking (Mitra et al. 2004b). Dmi3 encodes the CCaMK that is thought to integrate the calcium spiking signal (Levy et al. 2004; Mitra et al. 2004a), whereas Nsp1 and Nsp2 encode GRAS-domain proteins that are potential transcriptional activators (Kalo et al. 2005; Smit et al. 2005). The L. japonicus CCaMK (Sym15) gene is the orthologue of Dmi3 (Tirichine et al., in press) and, presumably, Sym35 could be an orthologue of Nsp1 or Nsp2 based on their similar mutant phenotypes (normal mycorrhization, no cortical cell divisions associated with nodule morphogenesis, but normal Nod-factor-induced calcium spiking and the ability to induce root hair deformation).

It seems likely that SymRK, Castor, Pollux, Sym24, calcium spiking, CcaMK, and Sym35 are all components of a signal transduction pathway leading to induction of early nodulation genes after Nod factor perception (Fig. 7). Because all of the respective mutants retain root hair deformation (Table 1), it is evident that root hair deformation is calcium spiking independent and is likely to be on a different pathway downstream of Nod factor perception (Fig. 7). A similar conclusion was reached previously based on the analysis of mutants of $M$. truncatula (Esseling et al. 2004). What, then, is it that induces the root hair deformation response, and could it be the calcium influx? Silencing of an $M$. truncatula calcium-dependent kinase caused abnormal root development, including root hair deformation, implying a possible role for calcium at some stage of root-hair deformation (Ivashuta et al. 2005). There also is the correlation observed here that all of the mutants that show some calcium flux also show some root hair deformation. However, this may be a rather poor correlation because the only mutants lacking root hair deformation in response to Nod factor are those which are likely to lack the Nod-factor re-

Table 1. Lotus japonicus mutants used in this study

\begin{tabular}{|c|c|c|c|c|c|}
\hline $\begin{array}{l}\text { Symbiosis gene } \\
\text { (previous name) }\end{array}$ & $\begin{array}{c}\text { Alleles tested } \\
\text { (original name) }\end{array}$ & Calcium flux & Calcium spiking & $\begin{array}{c}\text { Root hair } \\
\text { deformation }\end{array}$ & Reference \\
\hline Wild type & $\ldots$ & + & + & ++ & $\ldots$ \\
\hline \multirow[t]{3}{*}{ Nfrl (Sym1) } & $n f r 1-1(282-118)$ & - & - & - & Radutoiu et al. 2003 \\
\hline & $n f r 1-2(282-665)$ & $?$ & - & - & \\
\hline & $n f r 1-4(\mathrm{G} 71-23)$ & - & - & - & Sandal et al. 2006 \\
\hline Nfr5 (Sym-5) & $n f r 5-3$ (EMS323) & - & - & - & Madsen et al. 2003 \\
\hline \multirow[t]{2}{*}{ SymRK (Sym2, Sym21) } & symRK-3 (cAc41) & + & - & $++\left(\mathrm{sw}^{\mathrm{d}}\right)$ & Stracke et al. 2002 \\
\hline & symRK-7 (EMS61) & + & - & $++(\mathrm{sw})$ & \\
\hline \multirow[t]{2}{*}{ Castor (Sym4, Sym22) } & castor-1 (282-227) & + & $-^{\mathrm{a}}$ & $+(\mathrm{sw})$ & Senoo et al. 2000 \\
\hline & castor-3 (EMS46) & + & $-{ }^{\mathrm{a}}$ & $+(\mathrm{sw})$ & Imaizumi-Anraku et al. 2005 \\
\hline \multirow[t]{2}{*}{ Pollux (Sym23) } & pollux-1 (EMS70) & + & $-^{\mathrm{a}}$ & $+(\mathrm{sw})$ & Imaizumi-Anraku et al. 2005 \\
\hline & pollux-2 (EMS167) & + & $-^{\mathrm{a}}$ & $+(\mathrm{sw})$ & \\
\hline \multirow[t]{2}{*}{ Nup133 (Sym3) } & sym133-1 (5371-22) & + & $-{ }^{b}$ & $+(\mathrm{sw})$ & Schauser et al. 1998 \\
\hline & sym133-3 (cAc33.1) & + & $-\mathrm{b}$ & $+(\mathrm{sw})$ & Kanamori et al. 2006 \\
\hline Sym 24 & sym24 (EMS76) & + & - & ++ & Szczyglowski et al. 1998 \\
\hline \multirow[t]{2}{*}{ CCaMK (Sym15) } & ccamk-1 (282-1078) & + & $t^{\mathrm{c}}$ & ++ & Schauser et al. 1998 \\
\hline & ccamk-2 (cAc57.9) & + & $+^{\mathrm{c}}$ & $++(\mathrm{sw})$ & Senoo et al. 2000 \\
\hline \multirow[t]{2}{*}{ Sym6 } & sym6-2 (1962-124) & + & + & $+(\mathrm{sw})$ & Schauser et al. 1998 \\
\hline & sym30 (EMS126) & + & + & $+(\mathrm{sw})$ & Szczyglowski et al. 1998 \\
\hline Sym70 (sym35) & sym70-2 (cAc18.4) & + & $+^{\mathrm{c}}$ & ++ & Kawaguchi et al. 2002; Sandal et al. 2006 \\
\hline $\operatorname{Nin}(\operatorname{Sym} 20)$ & nin-7 (KL577) & + & + & ++ & Schauser et al. 1999 \\
\hline
\end{tabular}

${ }^{\text {a }}$ These data on calcium spiking were described previously (Imaizumi-Anraku et al. 2005).

${ }^{b}$ These data on calcium spiking were described previously (Kanamori et al. 2006).

${ }^{\mathrm{c}}$ These data on calcium spiking have been submitted for publication (Tirichine et al., Murakami et al.).

${ }^{\mathrm{d}} \mathrm{sw}=$ swollen.

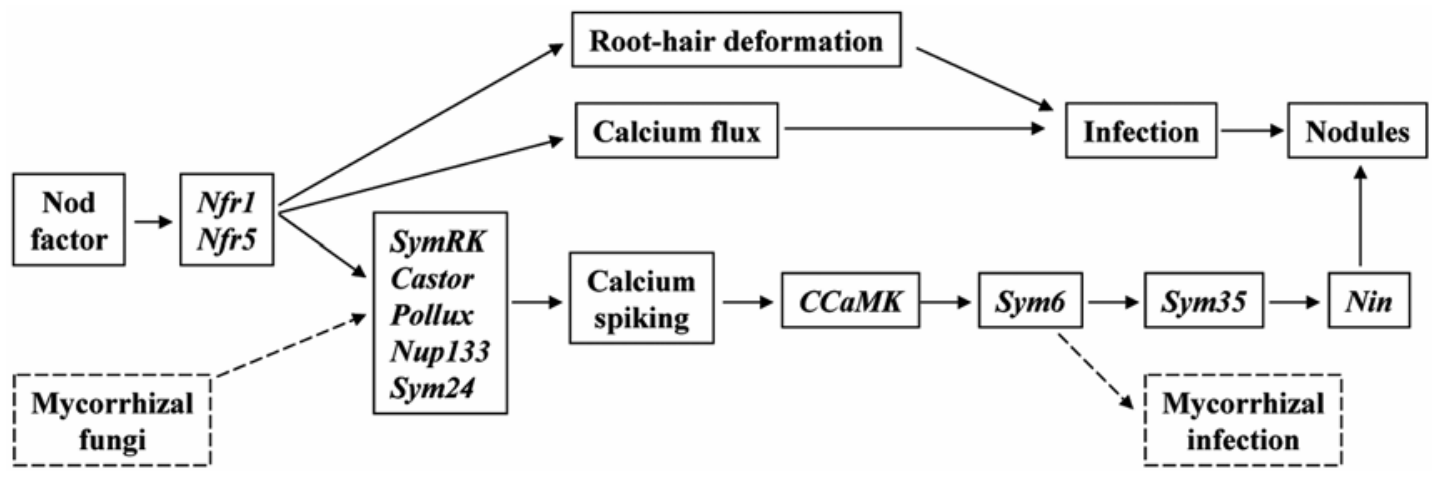

Fig. 7. Model relating Lotus japonicus symbiotic loci to nodulation (Nod)-factor signaling events. Mutations in $n f r l$ and $n f r 5$ encoding the predicted Nodfactor receptor (Radutoiu et al. 2003) blocked Nod-factor induced calcium flux, calcium spiking, and root-hair deformation. Mutations in symRK, castor, pollux, nup133, and sym24 blocked calcium spiking but not calcium flux; this, together with the observation that calcium spiking can be induced at low levels of Nod-factor but calcium flux cannot, shows that calcium flux is a separate response from calcium spiking. The fact that root hair deformation is induced by low concentrations of Nod factors that do not induce calcium flux shows that the observed calcium flux cannot be required for root-hair deformation. Mutations in sym6, ccamk, sym35, and nin do not block either calcium spiking or calcium flux. The symRK, castor, pollux, nup133, ccamk, sym6, and sym24 mutants are defective for early stages of mycorrhization (Kistner et al. 2005) and, therefore, are placed on a common pathway. The nin and sym35 mutants are blocked for both infection thread growth and nodule morphogenesis (Schauser et al. 1998, 1999). This simple linear model cannot place all events into a simple signaling pathway because the sym6 mutation appears to initiate nodule morphogenesis (Schauser et al. 1998; Szczyglowski et al. 1998). In principle, the nin, sym35, and sym6 loci (as well as others) could contribute to infection events as well as induction of nodule morphogenesis. 
ceptor. Root hair deformation in both $M$. truncatula (Catoira et al. 2000) and L. japonicus can be induced by Nod factor at concentrations up to three orders of magnitude lower than that required to induce the calcium flux; this demonstrates that the calcium flux that we and others (Ben Amor et al. 2003; Cardenas et al. 1999; Shaw and Long 2003; Walker et al. 2000) have measured shortly after Nod factor addition is not the driver for root hair deformation. A similar conclusion can be drawn based on the relatively high concentration of Nod factor required to induce the calcium influx and concomitant membrane depolarization in M. truncatula (Felle et al. 1998, 1999, 2000).

What, then, is the significance of the observed calcium flux and membrane depolarization that require high levels of Nod factor? We believe that, during the first contact between the plant root and the bacteria in the rhizosphere, it is unlikely that Nod factor will be present at high enough concentrations to activate a calcium flux in root hair cells. Rather, at this early stage, we propose that only root hair deformation and calcium spiking would be induced. However, when the bacteria are trapped inside an infection focus of a curled root hair cell, sufficient Nod factor could be generated by the growing population of bacteria and then be perceived by the plant to allow induction of a calcium flux. In this model, the calcium flux is induced considerably later than the calcium spiking and root hair deformation responses and, indeed, it has been observed that the calcium flux can be induced in root hair cells that already have been induced for calcium spiking (Shaw and Long 2003; Walker et al. 2000). We suggest that a role for the calcium flux may be the activation of infection thread growth. Support for such a model comes from the analysis of infection thread initiation in vetch by nodulation mutants of Rhizobium leguminosarum (Walker and Downie 2000). A nodO/nodE double mutant of $R$. leguminosarum bv. viciae induced strong root hair deformation and formed many infection foci; however, infection thread growth was very seldom initiated. NodE is involved in attachment of the appropriate acyl groups to the Nod factor (Spaink et al. 1991) and NodO is a secreted protein that forms cation-selective pores in membranes (Sutton et al. 1994) and, therefore, has the potential to catalyze calcium or potassium movements across plant cell membranes. Restoration of either nodO or nodE to the double mutant restored infection thread growth, suggesting that a NodO-induced ion flux across the membrane may compensate for an infection defect associated with inappropriate Nod factor production (Walker and Downie 2000). Because normal infection occurred with the nod $O$ mutant, the wild-type Nod factor may induce a localized ion flux, functionally equivalent to that predicted to be induced by NodO. Support for such a model also comes from the observations that a Sinorhizobium meliloti mutant, which produced a Nod factor that was not fully decorated, induced root hair deformation and infection foci but no infection thread growth. This was taken to imply a role for specific recognition being required for infection thread initiation compared with root hair deformation (Ardourel et al. 1994). Significantly, such a Nod factor is unlikely to induce the calcium flux (Shaw and Long 2003).

If this model for a calcium flux and membrane depolarization being required to initiate infection thread growth is correct, it implies that the identified genes encoding a Nod-factor receptor must play a role in perception of Nod factor at both low and high Nod-factor concentrations, because both the calcium flux and calcium spiking are both blocked by mutations in the $N f r l$ and $N f r 5$ genes. One way of discriminating between different concentrations of Nod factors could be to have receptors made up of different subunits. There are multiple genes of the Nfrl type in both M. truncatula (Limpens et al. 2003) and
L. japonicus (Radutoiu et al. 2003); therefore, different receptor complexes with different discrimination for Nod-factor structure and concentrations are a possibility. Intriguingly, the phenotype of silencing one of these genes (Lyk3) in M. truncatula resulted in seedlings that could induce root hair deformation and an infection pocket but were blocked for infection thread initiation (Limpens et al. 2003), rather similar to the phenotype of the nodO/nodE double mutant of R. leguminosarum (Walker and Downie 2000) and the S. meliloti mutant that made a modified Nod factor (Ardourel et al. 1994). The observation that mutation of $N f r l$ or $N f r 5$ blocks both calcium flux and calcium spiking responses suggests that both of these gene products should be integral components of a receptor and, possibly, other components could be added to confer different specificities of Nod factor perception.

\section{MATERIALS AND METHODS}

\section{Preparation of seedlings for assays of calcium and root hair deformation.}

L. japonicus accession Gifu B-129 (Stougaard and Beuselinck 1996) was used as the wild type and the mutants used were derived from Gifu B-129. The mutant alleles used are described in Table 1. Seed of $L$. japonicus were soaked in concentrated sulphuric acid for $10 \mathrm{~min}$, then washed five times in sterile water and imbibed overnight in sterile water. Imbibed seed were incubated in the dark on buffered nodulation medium (BNM) agar plates (Ehrhardt et al. 1992) at $5^{\circ} \mathrm{C}$, usually for 2 to 10 days before use. A plate carrying the seed then was incubated upside down at room temperature in the dark to allow the roots to grow vertically into the air. After 2 days, seedlings with similar root lengths (approximately $0.5 \mathrm{~cm}$ ) were transferred to filter papers (grade 0860; Schleicher and Schüll UK, London) placed on fresh BNM medium agar plates, and then the roots were covered by another filter paper to keep them moist. The bottom half of the plate was covered with black plastic and the plates then were incubated in a vertical position for $16 \mathrm{~h}$ under fluorescence light and $8 \mathrm{~h}$ of dark at $23^{\circ} \mathrm{C}$.

For calcium imaging experiments, the seedlings were placed into a small chamber made on a large cover glass using high vacuum grease (Dow Corning GMBH, Wiesbaden, Germany). The chamber was filled with $1 \mathrm{ml}$ of liquid BNM medium and the seedling was incubated at room temperature for at least 20 min before microinjection.

For root hair deformation assays, the seedlings were transferred to chambers made up of a glass microscope slide with a coverslip glued $2 \mathrm{~mm}$ above the slide. The chambers were filled with $1 \mathrm{ml}$ of BNM medium (Ehrhardt et al. 1992) containing $10 \mathrm{nM}$ Nod factor and left horizontal in the dark at room temperature for $20 \mathrm{~h}$. Roots were examined by light microscopy and root hair deformation was scored without prior knowledge of the treatment to the seedlings (presence or absence of Nod factor). Images were taken with a digital camera attached to an inverted microscope.

\section{Microinjection.}

Oregon Green 488 BAPTA-1-dextran 10,000 MW and Texas Red-dextran 10,000 MW (Molecular Probes, Eugene, OR, U.S.A.) stocks $(5 \mathrm{mM})$ each were made up in sterile water. Due to the higher fluorescence of Texas Red, 0.4- $\mu$ l aliquots of Texas Red were added to 3.6- $\mu$ l aliquots of Oregon Green. Immediately before each experiment, $1 \mu \mathrm{l}$ of $5 \times$ injection buffer $(0.75 \mathrm{M} \mathrm{KCl}, 0.45 \mathrm{M}$ Hepes, $\mathrm{pH} 7.0)$ was added to $4 \mu \mathrm{l}$ of mixed dye solution, which then was spun in a microcentrifuge for $5 \mathrm{~min}$ to remove any particulate matter.

Thin needles for microinjection were made using Borosilicate Glass Capillaries (1B120F-4; World Precision Instruments, Inc., 
Hertfordshire, England) and a computer-controlled electrode puller (model 773; Campden Instruments, Ltd., Loughborough, England). The optimized setting for pulling very thin needles was a heat intensity setting of 40 and a pulling force setting of 60 . The tips of these needles were examined under the light microscope and only needles with thin tips were selected for use in injection. The microinjection system was essentially that described by Wais and associates (2000). The needle first was back-loaded with approximately $0.2 \mu \mathrm{l}$ of dye solution using a thin, long pipette tip (Microloader; Eppendorf) and then the needle was filled with $1 \mathrm{M} \mathrm{KCl}$ solution. The cover glass containing a seedling was placed on an inverted epifluorescence microscope for microinjection. A reference electrode was placed into the BNM medium in the bath. The needle was controlled by a micromanipulator (PatchMan NP2; Eppendorf) and the tip of the needle was targeted to the apex of the growing root hair cells. The precise position of the needle tip was monitored by measuring the voltage through the needle. When the tip was in the cytoplasm, the voltage was slightly changed. Then, dyes were injected into the root hair cell by iontophoresis using a pulsed DC current of $10 \mathrm{nA}$ at 200-ms bursts at $5 \mathrm{~Hz}$. Injection proceeded until cells dimly fluoresced when viewed under illumination from a $100-\mathrm{W}$ mercury bulb through an fluorescein isothiocyanate filter block. After microinjection, root hairs were left at least $20 \mathrm{~min}$ before Nod-factor addition and only cells showing active cytoplasmic streaming were used for analysis. Nod factors, isolated from the reverse phase C18 column, and other compounds were added directly to the incubation chamber at the concentrations stated in the text.

We found that microinjecting dyes into L. japonicus Gifu root hairs was technically very demanding and considerably more difficult than $M$. truncatula, $M$. sativa, or $P$. sativum root hairs. The only root hairs we were able to microinject were those on seedlings grown for $24 \mathrm{~h}$ on agar, and the number of cells that were damaged as a result of microinjection was relatively high (approximately 60\%). For this reason, we had to be very selective about those root hairs used for imaging and we chose only those root hairs that retained active calcium streaming after microinjection (Fig. 1A). This meant that we usually were able to collect data on only one or sometimes two root hairs on any individual root. This limited the number of analyses that we technically were able to deal with.

\section{Fluorescence imaging.}

Fluorescence was imaged over the entire root-hair cell using a Nikon TE2000U inverted microscope coupled to a Hamamatsu Photonics digital CCD camera. An image splitter (Cairn Research, Faversham, Kent, U.K.) with an optimized polychromatic mirror was used to monitor both Oregon Green and Texas Red fluorescence and each image was collected sequentially using MetaFluor software. For Oregon Green fluorescence, the excitation wavelength was $488 \mathrm{~nm}$; an 11-nm bandpass was selected using an Optoscan Monochromator (Cairn Research) and an emission filter of $545 \pm 15 \mathrm{~nm}$ was used. For imaging of Texas Red, an excitation wavelength of $570 \mathrm{~nm}$ was used and the fluorescence was monitored with an emission filter of $620 \pm$ $20 \mathrm{~nm}$. Images were collected every $5 \mathrm{~s}$ with a 200-ms exposure using MetaFluor software, and the ratiometric traces were calculated by normalizing both average intensities and subtracting Texas Red from Oregon Green at each time point by following the formula $R=F_{(\mathrm{OG})}-F_{(\mathrm{TR})} \times A$, where $F_{(\mathrm{OG})}$ and $F_{(\mathrm{TR})}$ are the fluorescent intensities of Oregon Green and Texas Red, respectively, and $A$ is determined for each pair of traces to adjust both fluorescent intensities to similar values. In each injection, the fluorescence intensities of Oregon Green and Texas Red varied and, thus, the simple subtraction was not precise enough to analyze the cytosolic calcium level.
Nod-factor isolation and analysis.

Nod factor was isolated from the culture supernatant of $M$. loti R7A carrying pMP2112 (Lopez-Lara et al. 1995) essentially as described previously (Firmin et al. 1986). Briefly, Nod factor from a 2-liter culture induced with naringenin $(1 \mu \mathrm{M})$ was loaded onto a C18:1 reverse phase column (Sep Pak, Waters) and sequentially eluted with $2.5 \mathrm{ml}$ each of 40,60 , and $80 \%$ methanol/water. Samples from the $80 \%$ elution then were applied to a reverse phase $\mathrm{C} 18$ high-performance liquid chromatography column and eluted isocratically with $47 \%$ acetonitrile in water. The eluate was monitored at $206 \mathrm{~nm}$ and the molecular masses of the peaks were analyzed using a surface-enhanced laser desorption ionization-time of flight mass spectrometer $(\mathrm{Ci}-$ phergen, Fremont, CA, U.S.A.). The peak corresponding to the mass of NodMl-V (C18:1, Me, Cb, and AcMeFuc) as described previously (Lopez-Lara et al. 1995) was collected and its concentration determined using a molar extinction coefficient of 6,000 at $206 \mathrm{~nm}$. CHAPS was added to a final concentration of $0.01 \%$ and the Nod factor was diluted at least 1,000-fold when added to seedlings. End point dilution assays demonstrated that root hair deformation could be induced down to an estimated concentration of $10^{-12} \mathrm{M}$ Nod factor.

\section{ACKNOWLEDGMENTS}

The research was supported by a John Innes Foundation studentship and an Overseas Research Student award to H. Miwa, support from the BBSRC and the John Innes Centre to J .A. Downie and G .E. D. Oldroyd, a David Phillips Fellowship from the BBSRC to G .E. D. Oldroyd, and, in part, by a European Union grant RTN-CT-2003-505227 (INTEGRAL). J. Stougaard, M. Parniske, K. Szczyglowski, M. Kawaguchi, and their colleagues generously gave us seed of the mutants used in this study. We thank J. Graham and G. Calder for advice on setting up the microscopy and microinjection.

\section{LITERATURE CITED}

Ane, J. M., Kiss, G. B., Riely, B. K., Penmetsa, R. V., Oldroyd, G. E. D., Ayax, C., Levy, J., Debelle, F., Baek, J. M., Kalo, P., Rosenberg, C., Roe, B. A., Long, S. R., Denarie, J., and Cook, D. R. 2004. Medicago truncatula DMI1 required for bacterial and fungal symbioses in legumes. Science 303:1364-1367.

Ardourel, M., Demont, N., Debelle, F. D., Maillet, F., Debilly, F., Prome, J. C., Denarie, J., and Truchet, G. 1994. Rhizobium meliloti lipooligosaccharide nodulation factors-different structural requirements for bacterial entry into target root-hair cells and induction of plant symbiotic developmental responses. Plant Cell 6:1357-1374.

Ben Amor, B., Shaw, S. L., Oldroyd, G. E. D., Maillet, F., Penmetsa, R. V., Cook, D., Long, S. R., Denarie, J., and Gough, C. 2003. The NFP locus of Medicago truncatula controls an early step of Nod factor signal transduction upstream of a rapid calcium flux and root hair deformation. Plant J. 34:495-506

Cardenas, L., Feijo, J. A., Kunkel, J. G., Sanchez, F., Holdaway-Clarke, T. Hepler, P. K., and Quinto, C. 1999. Rhizobium Nod factors induce increases in intracellular free calcium and extracellular calcium influxes in bean root hairs. Plant J. 19:347-352.

Catoira, R., Galera, C., de Billy, F., Penmetsa, R. V., Journet, E. P., Maillet, F., Rosenberg, C., Cook, D., Gough, C., and Denarie, J. 2000. Four genes of Medicago truncatula controlling components of a nod factor transduction pathway. Plant Cell 12:1647-1665.

Charron, D., Pingret, J. L., Chabaud, M., Journet, E. P., and Barker, D. G. 2004. Pharmacological evidence that multiple phospholipid signaling pathways link rhizobium nodulation factor perception in Medicago truncatula root hairs to intracellular responses, including $\mathrm{Ca}^{2+}$ spiking and specific ENOD gene expression. Plant Physiol. 136:35823593.

Cook, D., Dreyer, D., Bonnet, D., Howell, M., Nony, E., and Vandenbosch, K. 1995. Transient Induction of a peroxidase gene in Medicago truncatula precedes infection by Rhizobium meliloti. Plant Cell 7:43-55.

den Hartog, M., Musgrave, A., and Munnik, T. 2001. Nod factor-induced phosphatidic acid and diacylglycerol pyrophosphate formation: A role for phospholipase $\mathrm{C}$ and $\mathrm{D}$ in root hair deformation. Plant J. 25:55-65.

de Ruijter, N. C. A., Rook, M. B., Bisseling, T., and Emons, A. M. C. 1998. Lipochito-oligosaccharides re-initiate root hair tip growth in Vicia 
sativa with high calcium and spectrin-like antigen at the tip. Plant J. 13:341-350

Downie, J. A. 1998. Functions of rhizobial nodulation genes. Pages 387402 in: The Rhizobiaseae. H. P. Spaink and P. J. J. Hooykaus, eds. Kluwer, Dordrecht, The Netherlands.

Duc, G., and Messager, A. 1989. Mutagenesis of pea (Pisum sativum L.) and the isolation of mutants for nodulation and nitrogen fixation. Plant Sci. 60:207-213.

Duc, G., Trouvelot, A., Gianinazzipearson, V., and Gianinazzi, S. 1989. First report of non-mycorrhizal plant mutants $\left(\mathrm{Myc}^{-}\right)$obtained in pea (Pisum sativum-L) and fababean (Vicia faba L). Plant Sci. 60:215-222.

Ehrhardt, D. W., Atkinson, E. M., and Long, S. R. 1992. Depolarization of alfalfa root hair membrane-potential by Rhizobium meliloti Nod factors. Science 256:998-1000.

Ehrhardt, D. W., Wais, R., and Long, S. R. 1996. Calcium spiking in plant root hairs responding to Rhizobium nodulation signals. Cell 85:673-681.

Endre, G., Kereszt, A., Kevei, Z., Mihacea, S., Kalo, P., and Kiss, G. B. 2002. A receptor kinase gene regulating symbiotic nodule development. Nature 417:962-966.

Engstrom, E. M., Ehrhardt, D. W., Mitra, R. M., and Long, S. R. 2002. Pharmacological analysis of nod factor-induced calcium spiking in Medicago truncatula. Evidence for the requirement of type IIA calcium pumps and phosphoinositide signaling. Plant Physiol. 128:1390-1401.

Esseling, J. J., Lhuissier, F. G. P., and Emons, A. M. C. 2004. A nonsymbiotic root hair tip growth phenotype in NORK mutated legumes: Implications for nodulation factor-induced signaling and formation of a multifaceted root hair pocket for bacteria. Plant Cell 16:933-944.

Felle, H. H., Kondorosi, E., Kondorosi, A., and Schultze, M. 1996. Rapid alkalinization in alfalfa root hairs in response to rhizobial lipochitooligosaccharide signals. Plant J. 10:295-301.

Felle, H. H., Kondorosi, E., Kondorosi, A., and Schultze, M. 1998. The role of ion fluxes in Nod factor signaling in Medicago sativa. Plant $\mathrm{J}$. 13:455-463.

Felle, H. H., Kondorosi, E., Kondorosi, A., and Schultze, M. 1999. Elevation of the cytosolic free $\mathrm{Ca}^{2+}$ is indispensable for the transduction of the nod factor signal in alfalfa. Plant Physiol. 121:273-279.

Felle, H. H., Kondorosi, E., Kondorosi, A., and Schultze, M. 2000. How alfalfa root hairs discriminate between Nod factors and oligochitin elicitors. Plant Physiol. 124:1373-1380.

Firmin, J. L., Wilson, K. E., Rossen, L., and Johnston, A. W. B. 1986. Flavonoid activation of nodulation genes in rhizobium reversed by other compounds present in plants. Nature 324:90-92.

Gehring, C. A., Irving, H. R., Kabbara, A. A., Parish, R. W., Boukli, N. M., and Broughton, W. J. 1997. Rapid, plateau-like increases in intracellular free calcium are associated with nod-factor-induced root-hair deformation. Mol. Plant-Microbe Interact. 10:791-802.

Harris, J. M., Wais, R., and Long, S. R. 2003. Rhizobium-induced calcium spiking in Lotus japonicus. Mol. Plant-Microbe Interact. 16:335-341.

Imaizumi-Anraku, H., Takeda, N., Charpentier, M., Perry, J., Miwa, H., Umehara, Y., Kouchi, H., Murakami, Y., Mulder, L., Vickers, K., Pike, J., Downie, J. A., Wang, T., Sato, S., Asamizu, E., Tabata, S., Yoshikawa, M., Murooka, Y., Wu, G. J., Kawaguchi, M., Kawasaki, S., Parniske, M., and Hayashi, M. 2005. Plastid proteins crucial for symbiotic fungal and bacterial entry into plant roots. Nature 433:527-531

Ivashuta, S., Liu, J. Y., Liu, J. Q., Lohar, D. P., Haridas, S., Bucciarelli, B., VandenBosch, K. A., Vance, C. P., Harrison, M. J., and Gantt, J. S. 2005. RNA interference identifies a calcium-dependent protein kinase involved in Medicago truncatula root development. Plant Cell 17:2911-2921.

Journet, E. P., Pichon, M., Dedieu, A., Debilly, F., Truchet, G., and Barker, D. G. 1994. Rhizobium meliloti Nod factors elicit cell-specific transcription of the ENOD12 gene in transgenic alfalfa. Plant J. 6:241-249.

Kalo, P., Gleason, C., Edwards, A., Marsh, J., Mitra, R. M., Hirsch, S., Jakab, J., Sims, S., Long, S. R., Rogers, J., Kiss, G. B., Downie, J. A., and Oldroyd, G. E. D. 2005. Nodulation signaling in legumes requires NSP2, a member of the GRAS family of transcriptional regulators. Science 308:1786-1789.

Kanamori, N., Madsen, L. H., Radutoiu, S., Frantescu, M., Quistgaard, E. M., Miwa, H., Downie, J. A., James, E. K., Felle, H. H., Haaning, L. L., Jensen, T. H., Sato, S., Nakamura, Y., Tabata, S., Sandal, N., and Stougaard, J. 2006. A nucleoporin is required for induction of $\mathrm{Ca}^{2+}$ spiking in legume nodule development and essential for rhizobial and fungal symbiosis. Proc. Natl. Acad. Sci. U.S.A. 103:359-364.

Kawaguchi, M., Imaizumi-Anraku, H., Koiwa, H., Niwa, S., Ikuta, A., Syono, K., and Akao, S. 2002. Root, root hair, and symbiotic mutants of the model legume Lotus japonicus. Mol. Plant-Microbe Interact. 15:17-26.

Kistner, C., Winzer, T., Pitzschke, A., Mulder, L., Sato, S., Kaneko, T., Tabata, S., Sandal, N., Stougaard, J., Webb, K. J., Szczyglowski, K., and Parniske, M. 2005. Seven Lotus japonicus genes required for transcriptional reprogramming of the root during fungal and bacterial symbiosis. Plant Cell 17:2217-2229.
Kurkdjian, A. C. 1995. Role of the differentiation of root epidermal cells in Nod factor (from Rhizobium meliloti)-induced root-hair depolarization of Medicago sativa. Plant Physiol. 107:783-790.

Levy, J., Bres, C., Geurts, R., Chalhoub, B., Kulikova, O., Duc, G., Journet, E. P., Ane, J. M., Lauber, E., Bisseling, T., Denarie, J., Rosenberg, C., and Debelle, F. 2004. A putative $\mathrm{Ca}^{2+}$ and calmodulin-dependent protein kinase required for bacterial and fungal symbioses. Science 303:1361-1364.

Limpens, E., Franken, C., Smit, P., Willemse, J., Bisseling, T., and Geurts, R. 2003. LysM domain receptor kinases regulating rhizobial Nod factor-induced infection. Science 302:630-633.

Lopez-Lara, I. M., Vandenberg, J. D. J., Thomasoates, J. E., Glushka, J., Lugtenberg, B. J. J., and Spaink, H. P. 1995. Structural identification of the lipo-chitin oligosaccharide nodulation signals of Rhizobium loti. Mol. Microbiol. 15:627-638.

Madsen, E. B., Madsen, L. H., Radutoiu, S., Olbryt, M., Rakwalska, M., Szczyglowski, K., Sato, S., Kaneko, T., Tabata, S., Sandal, N., and Stougaard, J. 2003. A receptor kinase gene of the LysM type is involved in legume perception of rhizobial signals. Nature 425:637-640.

Mitra, R. M., Gleason, C. A., Edwards, A., Hadfield, J., Downie, J. A., Oldroyd, G. E. D., and Long, S. R. 2004a. A Ca ${ }^{2+} /$ calmodulin-dependent protein kinase required for symbiotic nodule development: Gene identification by transcript-based cloning. Proc. Natl. Acad. Sci. U.S.A. 101:4701-4705.

Mitra, R. M., Shaw, S. L., and Long, S. R. 2004b. Six nonnodulating plant mutants defective for Nod-factor-induced transcriptional changes associated with the legume-rhizobia symbiosis. Proc. Natl. Acad. Sci. U.S.A. 101:10217-10222.

Oldroyd, G. E. D., and Downie, J. A. 2004. Calcium, kinases and nodulation signaling in legumes. Nat. Rev. Mol. Cell Biol. 5:566-576.

Perret, X., Staehelin, C., and Broughton, W. J. 2000. Molecular basis of symbiotic promiscuity. Microbiol. Mol. Biol. Rev. 64:180-201.

Radutoiu, S., Madsen, L. H., Madsen, E. B., Felle, H. H., Umehara, Y., Gronlund, M., Sato, S., Nakamura, Y., Tabata, S., Sandal, N., and Stougaard, J. 2003. Plant recognition of symbiotic bacteria requires two LysM receptor-like kinases. Nature 425:585-592.

Sandal, N., Petersen, T. R., Murray, J., Umehara, Y., Karas, B., Yano, K., Kumagai, H., Yoshikawa, M., Saito, K., Hayashi, M., Murakami, Y., Wang, X. W., Hakoyama, T., Imaizumi-Anraku, H., Sato, S., Kato, T., Chen, W. L., Hossain, M. S., Shibata, S., Wang, T. L., Yokota, K., Larsen, K., Kanamori, N., Madsen, E., Radutoiu, S., Madsen, L. H., Radu, T. G., Krusell, L., Ooki, Y., Banba, M., Betti, M., Rispail, N., Skot, L., Tuck, E., Perry, J., Yoshida, S., Vickers, K., Pike, J., Mulder, L., Charpentier, M. Muller, J., Ohtomo, R., Kojima, T., Ando, S., Marquez, A. J., Gresshoff, P. M., Harada, K., Webb, J., Hata, S., Suganuma, N., Kouchi, H., Kawasaki, S., Tabata, S., Hayashi, M., Parniske, M., Szczyglowski, K., Kawaguchi, M., and Stougaard, J. 2006. Genetics of symbiosis in Lotus japonicus: Recombinant inbred lines, comparative genetic maps, and map position of 35 symbiotic loci. Mol. Plant-Microbe Interact. 19:80-91.

Schauser, L., Handberg, K., Sandal, N., Stiller, J., Thykjaer, T., Pajuelo, E., Nielsen, A., and Stougaard, J. 1998. Symbiotic mutants deficient in nodule establishment identified after T-DNA transformation of Lotus japonicus. Mol. Gen. Genet. 259:414-423.

Schauser, L., Roussis, A., Stiller, J., and Stougaard, J. 1999. A plant regulator controlling development of symbiotic root nodules. Nature 402:191-195.

Senoo, K., Solaiman, M. Z., Kawaguchi, M., Imaizumi-Anraku, H., Akao, S., Tanaka, A., and Obata, H. 2000. Isolation of two different phenotypes of mycorrhizal mutants in the model legume plant Lotus japonicus after EMS-treatment. Plant Cell Physiol. 41:726-732.

Shaw, S. L., and Long, S. R. 2003. Nod factor elicits two separable calcium responses in Medicago truncatula root hair cells. Plant Physiol. 131:976-984.

Smit, P., Raedts, J., Portyanko, V., Debelle, F., Gough, C., Bisseling, T. and Geurts, R. 2005. NSP1 of the GRAS protein family is essential for rhizobial Nod factor-induced transcription. Science 308:1789-1791.

Spaink, H. P., Sheeley, D. M., Vanbrussel, A. A. N., Glushka, J., York, W. S., Tak, T., Geiger, O., Kennedy, E. P., Reinhold, V. N., and Lugtenberg, B. J. J. 1991. A novel highly unsaturated fatty-acid moiety of lipo-oligosaccharide signals determines host specificity of Rhizobium. Nature 354:125-130

Stougaard, J., and Beuselinck, P. R. 1996. Registration of GIFU B-129-S9 Lotus japonicus germplasm. Crop Sci. 36:476-476.

Stracke, S., Kistner, C., Yoshida, S., Mulder, L., Sato, S., Kaneko, T., Tabata, S., Sandal, N., Stougaard, J., Szczyglowski, K., and Parniske, M. 2002. A plant receptor-like kinase required for both bacterial and fungal symbiosis. Nature 417:959-962.

Sutton, J. M., Lea, E. J. A., and Downie, J. A. 1994. The nodulation-signaling protein NodO from Rhizobium leguminosarum biovar viciae forms ion channels in membranes. Proc. Natl. Acad. Sci. U.S.A. 91:9990-9994. 
Szczyglowski, K., Shaw, R. S., Wopereis, J., Copeland, S., Hamburger, D., Kasiborski, B., Dazzo, F. B., and de Bruijn, F. J. 1998. Nodule organogenesis and symbiotic mutants of the model legume Lotus japonicus. Mol. Plant-Microbe Interact. 11:684-697.

Tirichine, L. Imaizumi-Anraku, H., Yoshida, S., Murakami, Y., Madsen, L. H., Miwa, H., Nakagawa, T., Sandal, N., Albrektsen, A. S., Kawaguchi, M., Downie, J. A., Sato, S., Tabata, S., Kouchi, H., Parniske, M., Kawasaki, S., Stougaard, J. Deregulation of a $\mathrm{Ca}^{2+} / \mathrm{calmodulin}$ kinase leads to spontaneous nodule development. Nature. In press.

Truchet, G., Roche, P., Lerouge, P., Vasse, J., Camut, S., Debilly, F., Prome, J. C., and Denarie, J. 1991. Sulfated lipo-oligosaccharide signals of Rhizobium meliloti elicit root nodule organogenesis in alfalfa. Nature 351:670-673.

Wais, R. J., Galera, C., Oldroyd, G., Catoira, R., Penmetsa, R. V., Cook,
D., Gough, C., Denarie, J., and Long, S. R. 2000. Genetic analysis of calcium spiking responses in nodulation mutants of Medicago truncatula. Proc. Natl. Acad. Sci. U.S.A. 97:13407-13412.

Walker, S. A., and Downie, J. A. 2000. Entry of Rhizobium leguminosarum bv. viciae into root hairs requires minimal nod factor specificity, but subsequent infection thread growth requires nodO or nodE. Mol. PlantMicrobe Interact. 13:754-762.

Walker, S. A., Viprey, V., and Downie, J. A. 2000. Dissection of nodulation signaling using pea mutants defective for calcium spiking induced by Nod factors and chitin oligomers. Proc. Natl. Acad. Sci. U.S.A. 97:13413-13418

Yoshida, S., and Parniske, M. 2005. Regulation of plant symbiosis receptor kinase through serine and threonine phosphorylation. J. Biol. Chem. 280:9203-9209. 